\title{
A carta de intenções de David Bloor
}

\section{David Bloor's letter of intentions}

\author{
Fabrício Monteiro Neves \\ Professor do Programa de Pós-graduação em Ciências Sociais/Universidade Federal de Santa Maria. \\ fabriciomneves@gmail.com \\ Vinícius Teixeira Pinto \\ Mestrando do Programa de Pós-Graduação em Antropologia Social/Universidade Federal de Santa Catarina. \\ vinicius_t78@yahoo.com.br
}

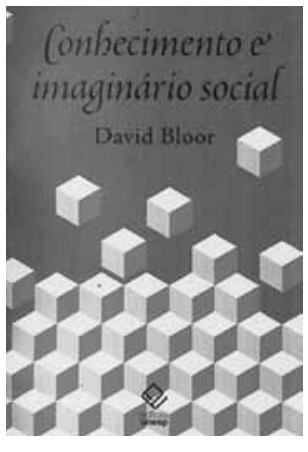

BLOOR, David. Conhecimento e imaginário social. São Paulo: Edunesp, 2009. 300p.
$\mathrm{T}$ odo campo de pesquisa científica institucionalizado em bases sólidas teve, em algum momento, de sintetizar suas diretrizes em proposições que funcionassem como um programa de pesquisa. Muitas vezes essa síntese foi um rompimento tão grande com o passado, que as críticas superaram o conteúdo cognitivo e caíram em disputas políticas, por espaço no campo ou por primazia na descoberta, ineditismo. O livro de David Bloor, Knowledge and social imagery, de 1976 - recentemente traduzido para português como Conhecimento e imaginário social (2009) -, desencadeou todos esses efeitos e ainda repercute em questões epistemológicas e políticas. Por quê?

Para procurar uma resposta, é preciso situar o livro e sua importância no cenário da sociologia do conhecimento científico, apresentar o debate travado com epistemólogos e cientistas e, é claro, compreender as principais contribuições de David Bloor e o surgimento de um novo campo de estudo.

Até a década de 1970, a sociologia era considerada capaz de estudar e compreender somente os processos sociais que deturpavam a produção do conhecimento científico, ou seja, que levavam ao erro, que desviavam a atividade científica de seu caminho em direção à verdade. Esse era o papel dos fatores sociais na construção do conhecimento. Dessa forma, no que tange ao conhecimento científico, cabia à sociologia, na divisão disciplinar do trabalho epistemológico, estudar o erro. Um conhecido representante desse tipo de estudo foi Karl Mannheim, o qual isentou o conhecimento científico da possibilidade de explicação sociológica.

Esse tipo de postura, digamos, acanhada, da investigação sociológica em relação ao conhecimento científico perdurou por um tempo. Contraditoriamente, será de outras áreas que a sociologia do conhecimento adquirirá artilharia pesada para contra-atacar. Esse contraataque começou nos anos 1930, com a publicação do seminal livro de Ludwik Fleck Genesis and development of a scientific fact, publicado originalmente em 1935. ${ }^{1}$ Tal livro permaneceu relativamente desconhecido, até que sua linha argumentativa fosse trazida à tona por Thomas 
Kuhn. No livro de Thomas Kuhn, As estruturas da revolução científica, publicado em 1964, a dinâmica de superação paradigmática era descrita em termos demasiadamente sociológicos para que continuassem a tratar a sociologia como uma subárea da epistemologia, ou seja, aquela preocupada com o erro, com os fatores de ordem social que afastava a verdade. ${ }^{2}$ Estava sendo gestado naquele momento um panorama simétrico de estudos para o conhecimento científico: verdade e erro deveriam ser tratados da mesma forma.

É nesse contexto que o trabalho de Bloor se insere, e em 1973 é publicado o artigo que indicaria uma nova perspectiva para a sociologia da ciência. Esse artigo é "Wittgenstein and Mannheim on the sociology of mathematics", texto que servirá de base para o livro aqui resenhado, Conhecimento e imaginário social, lançado originalmente em 1976. Nele veremos um programa de pesquisa claro, expondo princípios investigativos para superar o acanhamento sociológico na epistemologia, a divisão do trabalho, o tratamento assimétrico, que fora estabelecido entre sociologia e filosofia, verdade e erro.

Bloor defende que a sociologia pode ser usada para entender tanto o erro como o conhecimento certificado, verdadeiro. Para tanto, propõe quatro princípios básicos para a pesquisa sociológica do conhecimento científico. Esses princípios são: a) a causalidade, quer dizer, a sociologia se deve interessar pelas condições que ocasionam as crenças ou os estados de conhecimento; b) a imparcialidade quanto à verdade e o erro, racionalidade e irracionalidade, isto é, ambos os lados podem e devem ser explicados sociologicamente; c) a simetria, ou seja, tanto a verdade quanto o erro devem ser tratados segundo os mesmos tipos de causa; e d) a reflexidade, afinal, uma disciplina que propõe a explicação do conhecimento, através de suas variáveis sociais, deve entender que essas variáveis influenciam a produção sociológica; desse modo, a sociologia deve aplicar tais princípios a si mesma.

A partir desses princípios, Bloor cria um estatuto para o que vai ser chamado Programa Forte da Sociologia do Conhecimento. Como podemos ver, o programa é forte porque se contrapõe às concepções existentes na sociologia e nas áreas que se interessam pela questão do conhecimento científico, que consideraram somente a dimensão relativa às causas que deturparam o conhecimento verdadeiro. Assim, olhando rapidamente a história mais recente das áreas que tangenciavam a epistemologia, notam-se algumas objeções.

Uma dessas objeções é a de que o conhecimento científico possui autonomia em relação à sociedade. Para que essa concepção exista, é preciso separar o certo do errado, o que significará, por esse ponto de vista, que o conhecimento verdadeiro é obtido por meio da racionalidade e da lógica, sem interferência de outros componentes psicológicos ou sociais. Assim, a ciência é autoexplicativa. Tal pressuposto parece ignorar que os conceitos de verdadeiro e falso, racional e irracional são, antes de qualquer coisa, dependentes do contexto social. O programa forte se propõe a substituir essa objeção ao relacionar a atividade científica a processos sociais mais gerais, como a formação e dinâmica dos interesses.

Outra objeção apontada por Bloor é a empirista. Essa posição entende que, enquanto as influências sociais agem no sentido de prejudicar o alcance da verdade, o uso da percepção sensorial faz o contrário, servindo de contraprova a afirmações falsas. De acordo com os empiristas, a experiência sensorial produziria conhecimento por si só, diretamente extraído por meio dos sentidos. Tal objeção faz da sociologia do conhecimento sociologia do erro, posto que fatores sociais somente produziriam mediação deturpadora entre dado puro e consciência. 
Para Bloor, esse argumento ignora que, em primeiro lugar, os próprios sentidos de percepção estão sujeitos a condições singulares, e, em segundo lugar, o empirismo possui caráter individualista, diferente do conhecimento, que possui caráter social. Assim, Bloor defende que, mesmo quando ocorrem divergências individuais, as próprias normas de comunicação "encorajam o realinhamento" (p.32). Dessa forma a ciência não necessariamente representa uma realidade constatável diretamente. Portanto - e isso levou a que alguns autores acusassem o programa forte de behaviorismo ${ }^{3}-$, o conhecimento é a resultante do que nossas teorias mais aceitas dizem ser (crença anterior) e experiência.

A respeito desse ponto, Bloor diz ser necessário atentar para a importância da experiência sensorial, e não só supervalorizar nossas convenções mais arraigadas. De acordo com seu livro, mais do que nos voltarmos para as imperfeições da empiria, devemos perceber sua valiosa contribuição na construção do conhecimento. Isso significa dizer que o interesse do programa forte não está na percepção errônea, na falha e no erro, mas no conhecimento resultante da verdade de crenças anteriores e de nossas faculdades de percepção. Essa, diz Bloor, é a versão do empirismo incorporado à sociologia do conhecimento, ou seja, uma versão que distingue percepção e pensamento, "e que nossas percepções influenciam nosso pensamento mais do que nosso pensamento influencia nossas percepções" (p.58).

Não se trata, portanto, de um idealismo renovado - outra crítica feita ao programa forte - ou de assimetria, como Bruno Latour (1994) sustenta ao afirmar que o programa forte é realista para a sociedade e relativista para a natureza. Bloor (2009) deixa claro que não enxergar a confiabilidade da experiência sensorial pode tornar-se uma armadilha grave para os sociólogos da ciência, ou seja, é necessário perceber que o que está em jogo é outra coisa: a existência de fatores sociais em qualquer produção e reprodução de conhecimento. Desse modo, o postulado da simetria é criticado de forma equivocada, e Bloor responde a tais críticas no posfácio, incluído na edição brasileira da obra.

Desse modo, Bloor defende que no processo de produção de conhecimento há uma relação entre fatores sensoriais e fatores sociais, a crença resultante depende diretamente desses dois vetores. Conhecimento é relativo a preconcepções e, ainda, à experiência. Esses dois vetores são dependentes um do outro, já que a experiência sensorial não constitui propriamente o conhecimento, e não basta crer para que a crença se transforme em conhecimento sancionado. Assim, os críticos terão que abandonar também a crítica de que o programa forte reduziu a verdade à mera convenção social. Bloor (p.73) enfatiza que, a respeito da suposta arbitrariedade das convenções, "nem tudo pode tornar-se uma convenção"; afinal, "os contrangimentos sobre aquilo que pode se tornar convencional, ou uma norma, ou uma instituição, são a credibilidade social e a utilidade prática. As teorias têm que funcionar com grau de precisão e dentro do âmbito que convencionalmente se espera delas. Tais convenções não são nem autoevidentes, nem universais, nem estáticas".

Além do mais, alguns críticos do programa forte utilizaram o argumento da autorrefutação, já conhecido dos sociólogos do conhecimento desde Mannheim. Tais críticos afirmam que, se todo o conhecimento tem causas sociais (sendo vulgarmente considerado falso), também a sociologia estaria sujeita a essa mesma causação, o que implicaria também que seu conhecimento seria contaminado por elementos alheios às 'boas práticas cientificas', prejudicando necessariamente sua neutralidade. O que tal argumento ignora é que o fato 
de um conhecimento ter causas sociais não o torna falso, quer dizer que a verdade ou erro de um conhecimento "não tem nada a ver com o fato de ele ter uma causa" (p.37). Para dirimir possíveis dúvidas quanto a essa objeção é que Bloor (2009) incorporou aos princípios do programa forte a reflexividade. Desse modo, a sociologia deverá também, tanto quanto qualquer outra ciência, aplicar seus padrões de explicação a si mesma. O programa forte é também um constructo teórico condicionado.

A tardia publicação de Conhecimento e imaginário social em língua portuguesa causa prejuízos evidentes para a institucionalização da sociologia do conhecimento entre nós. Mais de trinta anos depois da versão original - após gerar toda celeuma e discussão, depois de ter inspirado novos programas sociológicos de pesquisa para o conhecimento, como o Programa Empírico do Relativismo de Harry Collins - parece que não há mais fôlego ou paciência para requentar discussões passadas.

No entanto, a publicação ainda pode afastar a sombra de anticiência, ideologia pósmoderna e irracionalismo que tal programa adquiriu entre os poucos envolvidos na discussão sociológica do conhecimento científico no Brasil. Para Bloor, estudar a ciência por meio do Programa Forte não é estar contra ela, pelo contrário, é uma alternativa científica para o entendimento da ciência. Afinal, é contraditório que nosso conhecimento possa apreender outros conhecimentos e culturas e não tenha capacidade de se voltar para nossas próprias práticas culturais, incluindo a ciência.

A importância de tal publicação em língua portuguesa está, sobretudo, em expor o outro lado da controvérsia que emergiu nos estudos sociais de ciência e tecnologia na década de 1990. O campo passou por rupturas que colocaram em lados opostos antigos aliados. Entre eles, Latour e Bloor. ${ }^{4}$ Enquanto o primeiro experimenta uma ampla recepção nas ciências sociais brasileiras, até expondo as críticas contra o segundo, este ainda não se havia defendido. Parece que agora chegou a sua hora. Com isso, a publicação tardia pode ajudar no incremento de reflexividade das ciências sociais brasileiras, promovendo a simetria dos argumentos entre duas diferentes perspectivas nos estudos sociais em ciência e tecnologia.

\section{NOTAS}

${ }^{1}$ Publicado no Brasil como Gênese e desenvolvimento de um fato científico, com tradução de Georg Otte e Mariana Camilo de Oliveira. Ver Fleck (2010).

${ }^{2}$ Deve-se dizer que o próprio Kuhn tratou de atenuar as consequências epistemológicas que seu livro gerou, principalmente aquelas que reforçavam a dimensão sociológica do fato científico. Para essa discussão, ver Kuhn (2006).

${ }^{3}$ Em especial, citado pelo próprio Bloor (2009), Slezak (1989).

${ }^{4}$ Especificamente conferir Bloor (1999) e Latour (1999).

\section{REFERÊNCIAS}

BLOOR, David.

Conhecimento e imaginário social. São Paulo:

Edunesp. 2009.

BLOOR, David.

Anti-Latour. Studies in History and Philosophy of

Science, New York, v.30, n.1, p.81-112. 1999.
BLOOR, David.

Wittgenstein and Mannheim on the sociology of mathematics. Studies in History and Philosophy of Science, New York, v.4, n.2, p.173-191. 1973.

FLECK, Ludwik.

Gênese e desenvolvimento de um fato científico. 
Trad., Georg Otte, Mariana Camilo de Oliveira. Belo Horizonte: Fabrefactum. 2010.

KUHN, Thomas.

O caminho desde a estrutura: ensaios filosóficos, 1970-1993. São Paulo: Edunesp. 2006.

LATOUR, Bruno.

For David Bloor... and beyond: a reply to David Bloor's 'Anti-Latour'. Studies in History and Philosophy of Science, New York, v.30, n.1, p.113-129. 1999.
LATOUR, Bruno.

Jamais fomos modernos. São Paulo: Editora 34. 1994.

SLEZAK, Peter.

Scientific discovery by computer as empirical refutation of the Strong Programme. Social Studies of Science, Thousand Oaks, v.19, p.563-600. 1989.

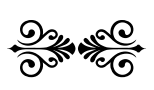

